\title{
Lung-Residing Metastatic and Dormant Neuroblastoma Cells
}

\author{
Liat Edry Botzer, ${ }^{*}$ Shelly Maman, ${ }^{*}$ Orit Sagi-Assif, \\ Tzipi Meshel, ${ }^{*}$ Ido Nevo, ${ }^{*}$ Tobias Bäuerle, ${ }^{\dagger}$ \\ Ilana Yron, ${ }^{*}$ and Isaac P. Witz* \\ From the Department of Cell Research and Immunology,* George \\ S. Wise Faculty of Life Sciences, Tel-Aviv University, Tel-Aviv, \\ Israel; and the Department of Radiology, German Cancer \\ Research Center, Heidelberg, Germany
}

The mechanism by which dormant tumor cells can begin growing after long periods of inactivity and accelerate disease recurrence is poorly understood. The present study characterizes dormant neuroblastoma (NB) cells, as well as metastatic cells, which reside in the same organ microenvironment. A xenograft model of human NB consisting of variants that generate nonmetastatic local tumors in the orthotopic inoculation site and variants that generate lung metastatic NB (MetNB) cells was developed in our laboratory. The present study shows that lungs of mice inoculated with nonmetastatic NB variants contain disseminated neuroblastoma (DisNB) human cells. Both DisNB and MetNB variants expressed a similar tumorigenicty phenotype in vivo, whereas the MetNB variants produced a heavy metastatic load and the DisNB variants produced no or little metastasis. A comparative in vitro characterization of MetNB and DisNB cells revealed similarities and differences. DisNB, but not MetNB cells, expressed the minimal residual disease markers PHOX2B and TH. MetNB cells demonstrated higher migratory capacity, an elevated matrix metalloproteinase (MMP) secretion, and a higher constitutive phosphorylation of extracellular signalregulated kinase (ERK) than DisNB cells. We suggest that characteristics common to both MetNB and DisNB cells were acquired relatively early in the metastatic process and the characteristics that differ between these variants were acquired later. We hypothesize that the DisNB cells are metastasis precursors, which may progress toward metastasis under certain microenvironmental conditions. (Am J Pathol 2011, 179:524-536; DOI: 10.1016/j.ajpath.2011.03.020)
Neuroblastoma (NB) is the most common extracranial solid tumor in children comprising $8 \%$ to $10 \%$ of all childhood cancers. More than half of these patients have a metastatic disease at diagnosis. ${ }^{1-3} \mathrm{NB}$ cells disseminate either by hematogenous spread, producing metastasis most frequently in bone marrow, bone, liver, and skin, or by lymphatic spread to regional and distant lymph nodes. ${ }^{4}$ Lung metastases are considered a terminal event representing a widely disseminated metastatic disease. ${ }^{5-6}$

Approximately $50 \%$ of children with high-risk NB that complete consolidation therapy develop early or late relapse, often from minimal residual disease in the form of circulating NB cells or micrometastases. ${ }^{7}$ Most of the children with NB present metastatic disease at diagnosis with poor outcome, despite intensive treatment protocols. ${ }^{8}$ The presence of circulating NB cells and/or NB micrometastasis may indicate a significant high-risk disease. ${ }^{9}$ However, the question whether NB micrometastases develop into metastatic disease is yet to be answered.

Previous studies from our laboratory were aimed to identify molecular pathways that are involved in NB metastasis. We focus on the cross talk between metastatic NB cells and components of their microenvironment, and on the downstream effects of such interactions.

We suggested that NB cells might use chemokinechemokine receptor axes in their progression to metastasis. For example the CXCR4-CXCL12 ${ }^{10-11}$ and the CX3CL1-CX3CR $1^{12}$ axes take part in extravasation, transendothelial migration and invasion thereby promoting progression. CXCR3 on the other hand fulfills antimalignancy functions. ${ }^{13}$

To advance the understanding of the molecular mechanisms that promote NB metastasis we developed an orthotopic mouse model for human NB metastasis. An orthotopic implantation of two human NB cell lines $(\mathrm{MHH}-$ NB11 and SH-SY5Y) into the adrenal gland of athymic nude mice yielded local adrenal tumors, as well as lung

\footnotetext{
Supported by a grant from Bonnie and Steven Stern (New York, NY). Accepted for publication March 29, 2011.

Address reprint requests to Isaac P. Witz, Ph.D., Department of Cell Research and Immunology, George S. Wise Faculty of Life Sciences, Tel-Aviv University, Tel-Aviv, 69978 Israel. E-mail: ipwitz@post.tau.ac.il.
} 
metastases. After repeated cycles of in vivo passages, local and lung metastatic variants were generated. ${ }^{14}$ The local variants form tumors at the orthotopic inoculation site and do not form lung metastasis (as judged by histopathology), whereas the metastatic variants from the same NB cell lines form local tumors as well as macroscopic lung metastasis after orthotopic inoculation into the adrenal gland. ${ }^{14}$ Originating in the same tumors, these variants have an identical genetic background. Genomic, proteomic, or transcriptomic differences between these variants can thus be ascribed to the differences in their metastatic phenotype.

This model system was primarily established to gain additional understanding of biological mechanisms leading to metastasis. The model system was used as a generic metastasis model rather than as a tool to characterize specific clinical manifestations of NB metastasis. Nonetheless, a small set of genes that were differentially expressed in the metastatic and the local variants could segregate stage 4 and stage 1 NB patients. ${ }^{15}$ The molecular signatures shared by metastatic NB variants and stage 4 NB patients, and the signature shared by local NB variants and stage 1 NB patients, highlights the translational significance of the orthotopic mouse model for human NB metastasis.

In the present study, we used the previously mentioned model of NB metastasis to examine the tumorogenicity and metastatic capacity of the local and metastatic NB variants. We show that nude mice orthotopically inoculated with local NB variants that do not form metastasis in the lungs, nonetheless, harbor disseminated NB (DisNB) cells in their bone marrow and lungs.

Two NB cell populations sharing the same genetic background, invading the same distant organ, but differing in their ability to create metastasis in this organ were thus obtained. The characteristics differentiating these populations may be those required from dormant micrometastatic tumor cells to progress toward metastasis. In this study, we performed a comparative phenotypic analysis of these two NB cell populations.

\section{Materials and Methods}

\section{Cell Cultures}

NB variants generated from the parental cell line $\mathrm{MHH}$ NB- $11^{16}$ (kindly provided by Dr. Torsten Pietsch, Department of Neuropathology, University of Bonn Medical Center, Bonn, Germany) and SH-SY5Y, as well as murine DA3 cells, were maintained in culture as previously described. ${ }^{14}$

\section{Animals}

Generation of metastatic neuroblastoma (MetNB) and disseminated neuroblastoma (DisNB) variants was performed in male athymic nude mice (BALB/c background) purchased from Harlan Laboratories Ltd. (Jerusalem, Israel) or from Charles River (Sulzfeld, Germany) and used for tumorigenicity and metastasis experiments. Mice (7to 10-weeks-old) were housed and maintained for ap- proximately 6 months in laminar flow cabinets under specific pathogen-free conditions at the animal quarters of Tel-Aviv University or at the central animal facility of the German Cancer Research Center (DKFZ). Experiments were performed in accordance with current regulations and standards of the Tel-Aviv University Institutional Animal Care and Use Committee and with the institutional guidelines of the local animal ethics committee of the central animal facility of the German Cancer Research Center (DKFZ).

\section{Orthotopic Inoculation of Tumor Cells}

Cells were harvested and transferred to RPMI 1640 medium supplemented with $5 \%$ to $10 \%$ Fetal Calf Serum (FCS). Only single-cell suspensions of greater than $90 \%$ viability (trypan blue exclusion) were used for injection. Anesthesia was induced either by ketamine $(100 \mathrm{mg} / \mathrm{kg}$ body mass; Kepro Deventer, The Netherlands) and 2\% xylazine $(10 \mathrm{mg} / \mathrm{kg}$ body mass; Medical Market, Tel Izhak, Israel) administered intraperitoneally or by a mixture of laughing gas (nitrous oxide; $1 \mathrm{~L} / \mathrm{min})$, oxygen $(0.5$ $\mathrm{L} / \mathrm{min}$ ), and isoflurane (1 to $1.5 \mathrm{vol}$. \%). Tumor cells ( $1 \times$ $10^{6} / 50 \mu \mathrm{L}$ ) were injected orthotopically into the adrenal gland. The injected volume was small enough to keep the mechanical pressure low to prevent leakage of cells out of the gland. Furthermore, a real-time PCR assay to determine the presence of human cells in nude mice (see as follows) indicated that nude mice injected intravenously with human NB cells contained such cells in their lungs 2 hours after inoculation. On the other hand, no such cells could be detected in the lungs of mice that received an intra-adrenal inoculation of the same cells, 2 hours as well as 24 hours after inoculation. These results clearly showed that there was no NB cell leakage into the asculature after an intra-adrenal inoculation.

The intra-adrenal inoculation required surgical exposure of the left adrenal gland under anesthesia, as previously described. ${ }^{14}$ Briefly, a left-side, high-paracostal approach to the abdomen allowed visualization of the cranial tip of the left kidney. A 27-gauge needle was introduced through the left adrenal fat pad into the adrenal gland after retraction of the left kidney. Special care was taken so as not to penetrate the back side of the adrenal gland. The peritoneum was closed by surgical stitching and the skin was adapted using clips. We monitored and verified the development of local tumors in the adrenal gland using an ultrasound imaging in vivo.

\section{Ultrasound Imaging of Tumors in the Adrenal Gland}

Mice were anesthetized by $2 \%$ inhalation of isoflurane (Halocarbon Products, River Edge, NJ) delivered with oxygen, using a breathing anesthetic delivery system. The high-resolution small animal ultrasound system (Vevo 770; VisualSonic, Toronto, Canada) was used for the visualization of adrenal tumors. Imaging settings were standardized and unchanged throughout the experiment. 


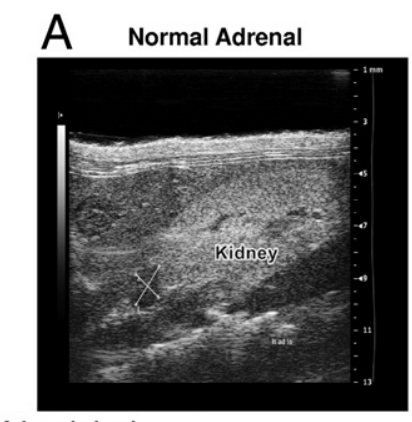

Adrenal gland

volume

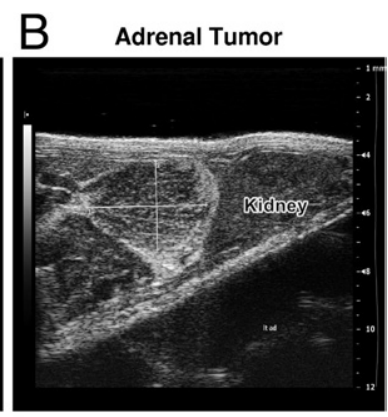

$55 \mathrm{~mm}^{3}$

Figure 1. Ultrasound imaging of adrenal tumors in vivo. MHH.Ad was inoculated orthotopically into the adrenal gland of nude mice. High-resolution ultrasound system was used to visualize adrenal tumors. A: Adrenal of mouse that did not develop a tumor. B: Adrenal of mouse that developed a tumor.

All mice inoculated with the both the local, as well as the metastatic variants developed adrenal tumors.

Tumor volume was calculated using the ellipsoid equation: $\pi / 6 \times$ length $\times$ width $\times$ height (Figure 1 ).

\section{Necropsy Procedure and Organ Harvesting}

Mice were sacrificed and the local (adrenal) tumor, lungs, bone marrow, and other peritoneal organs suspected to harbor metastases were removed. Tumor lesions and organs were either fixed in $4 \%$ buffered formalin and embedded in paraffin for histopathological examination, or cultured for the isolation of human NB cells.

For the culturing of bone marrow cells, bone marrow was isolated from the tibias and femurs. The bone marrow was triturated using a 25-gauge needle in RPMI 1640 medium. The cells were then washed twice in PBS and resuspended in RPMI 1640 medium.

\section{Preparation and RT-PCR}

Total RNA was isolated from cells or organs using the EZ-RNA kit (Biological Industries, Beit Haemek, Israel), according to the manufacturer's instructions.

Pieces of lungs and sternum of inoculated mice were harvested and immediately placed on dry ice. RNA was

isolated from frozen tissues and used for generation of first-strand CDNA synthesis, using the M-MLV Reverse Transcriptase (Ambion, Inc., Austin, TX) according to the manufacturer's instructions.

\section{Determination of the Presence of Human Cells in Mouse Tissues by RT-PCR}

PCR oligonucleotide primers were designed according to sequences derived from the National Center for Biotechnology Information database, and described in Table 1. Primers for this reaction were designed to react specifically with the human plasminogen activator receptor, urokinase type (PLAUR) sequence and have no cross reactivity with the mouse PLAUR sequence.

PLAUR oligonucleotides were used for the amplification of $589 \mathrm{bp}$. MHH-NB-11 cells were used as source for human cells, serving as positive control. Murine DA3 cells were used as negative control.

The PCR reaction for human PLAUR in mouse tissues was: $94^{\circ} \mathrm{C}$ for 3 minutes, followed by 45 cycles of: $94^{\circ} \mathrm{C}$ for 40 seconds, $64^{\circ} \mathrm{C}$ for 1 minute, and $72^{\circ} \mathrm{C}$ for 40 seconds.

\section{RT-PCR Reactions}

Quantification of cDNA targets was performed on Rotorgene 6000TM (Corbett life science, Sydney, Australia), using Rotor gene 6000 series software. All reactions were performed in duplicates. Transcripts were detected using SYBR Green I (Thermo Fisher scientific, Abgene, England) according to the manufacturer's instructions. Optimal reaction conditions for amplification of target genes were performed according to manufacturer's recommendation. PCR amplification was performed over 40 cycles $\left(95^{\circ} \mathrm{C}\right.$ for 15 seconds, $59^{\circ} \mathrm{C}$ for 20 seconds, and $72^{\circ}$ for 15 seconds). Dissociation curves for each primer set indicated a single product and no-template controls were negative after 40 cycles. The sequence of the primers used is detailed in Table 1.

For the expression level of paired-like Homeobox 2B (PHOX2B) and tyrosine hydroxylase $(\mathrm{TH})$ results were normalized to ribosomal RNA (rS9) as an internal control. For the detection of human NB cells in mouse tissues, two

Table 1. PCR Oligonucleotide Primers

\begin{tabular}{|c|c|c|c|c|}
\hline & Reaction specificity & Accession no. & $\begin{array}{c}\text { Primer } \\
\text { designation }\end{array}$ & Sequence \\
\hline PCR & Human & NM_001005376 & $\begin{array}{l}\text { PLAUR (365)-S } \\
\text { PLAUR (954)-AS }\end{array}$ & $\begin{array}{l}\text { 5'-GTCACCTATTCCCGAAGCCG-3' } \\
5^{\prime} \text {-CGGTACTGGACATCCAGGTCT-3' }\end{array}$ \\
\hline RT-PCR & Human & $\begin{array}{l}\text { NM_000360 } \\
\text { NM_003924.3 }\end{array}$ & $\begin{array}{l}\text { TH (1218)-S } \\
\text { TH (1339)-AS } \\
\text { PHOX2B (592)-S } \\
\text { PHOX2B (711)-AS }\end{array}$ & $\begin{array}{l}\text { 5'-TGTACTGGTTCACGGTGGAGTT-3' } \\
\text { 5'-AATCTCAGGCTCCTCAGACA-3' } \\
\text { 5'-TACGCCGCAGTTCCTTACAA-3', } \\
\text { 5'-GAAGACCCTTTCCAGCTCTTT-3' }\end{array}$ \\
\hline & Human & NM_004048 & $\begin{array}{l}\beta 2 \mathrm{~mol} / \mathrm{L}(415)-S \\
\beta 2 \mathrm{~mol} / \mathrm{L}(484)-A S\end{array}$ & $\begin{array}{l}5^{\prime}-\text { ATGTAAGCAGCATCATGGAG-3' } \\
5^{\prime}-\text { AAGCAAGCAGAATTTGGAAT-3' }\end{array}$ \\
\hline & Humanandmice & NM_001013 & $\begin{array}{l}\text { RS9(341)-S } \\
R S 9(490)-A S\end{array}$ & $\begin{array}{l}5^{\prime} \text {-TTACATCCTGGGCCTGAAGAT-3' } \\
5^{\prime} \text {-GGGATGTTCACCACCTGCTT-3' }\end{array}$ \\
\hline
\end{tabular}

The primer designation indicates the first nucleotide according to sequences derived from the National Center for Biotechnology Information database and the direction of the primer, sense (S) or anti-sense (AS).

PLAUR, plasminogen activator receptor, urokinase type; TH, tyrosine hydroxylase. 
pairs of specific primers that recognize human mRNA were used in each reaction. A set of primers for $\beta 2 \mathrm{M}$, which does not react with mouse cDNA and a set of primers for the normalizing RS9 mRNA, which reacts with human as well as mouse cells, generating an identical product, enabling to compare a relative amount of mRNA copies in organs harvested from mice that were inoculated with DisNB or MetNB variants.

\section{Antibodies}

The following human specific antibodies were used for flow cytometry: phycoerythrin conjugated anti-CD56, $0.03 \mu \mathrm{g} / \mathrm{sample}$ (DakoCytomation, Glostrup, Denmark); anti-CX3CL1, $1 \mu \mathrm{g} /$ sample (Torrey Pines Biolabs, Inc., East Orange, NJ); anti CX3CR1, $1 \mu \mathrm{g} / \mathrm{sample}$ and anti-Ckit, $0.5 \mu \mathrm{g} / \mathrm{sample} \mathrm{(YB5.B8,} \mathrm{eBioscience,} \mathrm{San} \mathrm{Diego,}$ CA); anti-CXCR3, $2.5 \mu \mathrm{g} / \mathrm{sample}$ (49801), anti-CXCR5, $2.5 \mu \mathrm{g} / \mathrm{sample}$ (51505), anti-CXCR6, $2.5 \mu \mathrm{g} / \mathrm{sample}$ (56811), (R\&D Systems); anti-CD44, $0.25 \mu \mathrm{g} / \mathrm{sample}$ (IM7, BioLegend, San Diego, CA); anti-CXCR4, $0.5 \mu \mathrm{g} /$ sample (B-R24; Diaclone, Stamford, CT), anti-CD133 $0.05 \mu \mathrm{g} / \mathrm{sample}$ (293C3, Miltenyi Biotec), anti-CD34 0.5 $\mu \mathrm{g} / \mathrm{sample}$ (581, BD Biosciences Pharmingen, San Diego, CA). Anti-Human Leukocyte Antigen (HLA)-A-B-C, $\mathrm{mAb}(\mathrm{W} 6 / 32)^{17}$ and anti-H-2 mAb (20-8-4S) ${ }^{18}$ were kindly provided by Dr. R. Ehrlich, Department of Cell Research and Immunology, Tel-Aviv University, and were used at $1: 500$ and 1:3000, respectively.

Fluorescein isothiocyanate-conjugated goat antimouse IgG and goat anti-rabbit IgG (Jackson Immuno ResearchLaboratories, West Grove, PA) were used at 0.5 $\mu \mathrm{g} / \mathrm{sample}$ as secondary antibodies for flow cytometry.

For Western blot analysis: anti-extracellular signal-regulated kinase2 (C-14, Santa Cruz Biotechnology, Inc., Santa Cruz, CA) and anti-phosphorylated-ERK1/2 (R\&D Systems) at 1:1000; anti-phosphorylated AKT (S473, R\&D Systems) at 1:2000; anti AKT1 (B-1, Santa Cruz Biotechnology at 1:1000; anti-paracingulin (CGNL1, Zymed Laboratories Inc., San Francisco, CA) at 1:500; anti-matrix metalloproteinase (MMP)-2 and anti-MM9 at 1:500 $\mu \mathrm{g} / \mathrm{mL}$ (EMD Chemicals, Inc., San Diego, CA).

Horseradish peroxidase-conjugated goat anti-mouse antibodies and rabbit anti-goat antibodies were used according to the manufacturer's instructions (Jackson ImmunoResearch Laboratories).

\section{Flow Cytometry}

The $5 \times 10^{5}$ cells were washed with FACS medium (RPMI 1640 medium supplemented with 5\% FCS and 0.01\% sodium azide). Samples were incubated for 1 hour at $4^{\circ} \mathrm{C}$ with the relevant primary antibody. After a wash with FACS medium, cells were incubated for 1 hour at $4^{\circ} \mathrm{C}$ with fluorescein isothiocyanate-conjugated secondary antibody. For double staining, we preformed another wash with FACS medium; cells were then incubated for an additional 1 hour at $4^{\circ} \mathrm{C}$ with another relevant antibody (conjugated with phycoerythrin). After an additional wash, antigen expression was determined using FACSort
(Becton Dickinson, Mountain View, CA) and CellQuest (Becton Dickinson) software. Baseline staining was obtained by labeling the cells with secondary antibodies alone. Statistical analysis was performed using the Student's $t$-test.

\section{Western Blotting}

NB cells were lysed with RIPA buffer ( $20 \mathrm{mmol} / \mathrm{L}$ Tris, $\mathrm{pH}$ $8,150 \mathrm{mmol} / \mathrm{L} \mathrm{NaCl}, 1 \% \mathrm{NP}-40,0.1 \% \mathrm{SDS}, 0.75 \%$ deoxycholate, $5 \mathrm{mmol} / \mathrm{L}$ EDTA, pH 8, 3 mmol/L EGTA, pH 8, 20 $\mathrm{mmol} / \mathrm{L}$ sodium phosphate, $\mathrm{pH} 7.6,2 \mathrm{mmol} / \mathrm{L}$ sodium orthovanadate, $5 \mathrm{mmol} / \mathrm{L} \mathrm{NaF}, 5 \mathrm{mmol} / \mathrm{L}$ sodium pyrophosphate, $\mathrm{pH} 7.6,2 \mathrm{ng} / \mathrm{mL}$ aprotinin, $2 \mathrm{ng} / \mathrm{mL}$ leupeptin, and $1 \mathrm{mmol} / \mathrm{L}$ phenylmethylsulfonyl fluoride). Cell lysates were incubated for 20 minutes on ice, and cleared by centrifugation for 20 minutes at $16,000 \mathrm{~g}, 4^{\circ} \mathrm{C}$. After the addition of Laemmli sample buffer, the lysates were boiled for 10 minutes, resolved on SDS-polyacrylamide gel electrophoresis (PAGE), and transferred onto nitrocellulose membrane. The target proteins were detected by using a relevant primary antibody and suitable horseradish peroxidase-conjugated secondary antibodies, which are described in the Antibodies section. Bands were visualized by enhanced chemiluminescence (ECL) (Amersham, Buckinghamshire, United Kingdom) and autoradiographed by exposure to Fuji film. The amount of the relevant protein in the lanes was estimated by densitometry and was calculated in reference to the loading control in the lane using Scion Image software (Scion, Frederick, MD).

\section{Wound Healing Assay}

Cells were grown in six-well plates coated with $10 \mu \mathrm{g} / \mathrm{mL}$ fibronectin (Biological Industries). On confluence, the cell monolayer was wounded with a plastic tip, then washed twice with RPMI 1640 medium, and replaced with fresh growth medium. Closure of the denuded area was monitored using an inverted microscope (Eclipse TE 2000-S; Nikon, Enfield, CT) and fitted with a digital camera (DXM1200F; Nikon). Photograph documentation was taken at days 1, 2, and 3 after the wounding.

\section{Gelatin Substrate Zymography}

NB cells were incubated overnight in growth medium. After 24 hours the medium was replaced by serum-free RPMI 1640 medium for an additional 24 hours. The presence of matrix metalloproteinases in the conditioned medium was determined by separation on $7.5 \%$ SDS-PAGE containing $0.1 \%$ gelatin as substrate. After electrophoresis, gels were washed three times in $50 \mathrm{mmol} / \mathrm{L} \mathrm{Tris-} \mathrm{HCl}$, pH 7.4, containing 2.5\% Triton X-100. The gels were then washed three times in $50 \mathrm{mM}$ Tris- $\mathrm{HCl}$ buffer, $\mathrm{pH} 7.4$, followed by incubation in a buffer, consisting of 50 $\mathrm{mmol} / \mathrm{L}$ Tris- $\mathrm{HCl}, \mathrm{pH} 7.4,0.02 \%$ sodium azide, and 10 $\mathrm{mmol} / \mathrm{L} \mathrm{CaCl} 2$ for 48 hours at $37^{\circ} \mathrm{C}$. After three additional washes in double-distilled $\mathrm{H}_{2} \mathrm{O}$, gels were stained with $0.25 \%$ Coomassie blue and de-stained in 20\% methanol and $10 \%$ glacial acetic acid, and clear bands of protein degradation were visualized. 


\section{In Vitro Assays for Proliferation and Viability}

NB cells were harvested from $80 \%$ confluent monolayer cultures and seeded at a density of $1 \times 10^{4}$ to $10^{5}$ cells per well in a 96-well, flat-bottomed, tissue culture plate. Proliferation and viability under normal conditions or under doxorubicin/desferrioxamine (DOX/DFX) treatment were monitored in triplicates using a XTT-based assay after 0, 24, 48, 72, and 96 hours, according to the manufacturer's instructions (Biological Industries). Absorbance at $450 \mathrm{~nm}\left(\mathrm{OD}_{450}\right)$ was determined for each well using an automated microplate reader (SpectraMax 190; Molecular Devices Corp., Sunnyvale, CA). Subtraction of nonspecific readings (measured at $630 \mathrm{~nm}$ ) was automatically performed. To obtain the percentage of cell growth or cell viability, the $\mathrm{OD}_{450}$ of the cells (in each time point of Dox/DFX treatment) was divided by the $\mathrm{OD}_{450}$ of the cells at the initial time point of the experiment.

\section{ERK1/2 and AKT Phosphorylation}

NB cells were plated for 24 hours in growth medium. After 24 hours the medium was replaced with serum-free medium and cells were incubated for additional 24 hours. Cells were washed with ice-cold PBS and lysed. The lysates were resolved on SDS-PAGE and transferred onto nitrocellulose membrane as previously described. Total ERK2 or AKT, and phosphorylated ERK1/2 or AKT proteins were detected by using the relevant primary antibodies and suitable horseradish peroxidase-conjugated secondary antibodies (previously described). The amount of total ERK2/ AKT was detected after stripping the membrane from the phosphorylated antibodies and exposing it to the relevant antibodies. Phosphorylation was calculated in reference to total protein in the lane as measured by densitometry using Scion Image software (Scion).

\section{Statistical Analysis}

An unpaired Student's t-test was used to compare in vitro results. The analysis of mouse survival was computed by the Kaplan-Meier method.

\section{Results}

Identification of DisNB Cells in the Bone Marrow and Lungs of Nude Mice Inoculated with Nonmetastatic Cells

We have previously demonstrated that $50 \%$ of mice inoculated orthotopically with cells of the metastatic variants (either MHH.Lu3 or SY5Y.Lu2) formed lung metastasis within a period of 6 to 10 weeks after inoculation. However, none of the mice inoculated orthotopically with the nonmetastatic variants (either $\mathrm{MHH}$.Ad or SY5Y.Ad originating from NB MHH or SY5Y tumors, respectively) formed such metastasis up to 16-weeks postinoculation. Immunohistochemical examination using synaptophysin (an NB cell marker) did not detect NB cells in the lungs or bone marrow of these mice. ${ }^{14}$ The possibility was raised that the nonmetastatic cells can reach the metastatic target organs, but are unable to propagate and form detectable metastases. To test this possibility, we cultured target organs and searched these cultures for human NB cell outgrowth, as well as for human RNA (described as follows).

Lungs and bone marrow of nude mice orthotopically inoculated with nonmetastatic cells (either $\mathrm{MHH}$.Ad or SY5Y.Ad variants) were put in culture in an attempt to possibly discover DisNB cells in these organs. Indeed, after a culture period of 6 to 12 weeks, an outgrowth of human NB cells was detected in the culture flasks. These cells were immunophenotyped by flow cytometry for the expression of human and mouse major histocompatibility complex class 1 antigens and for the expression of CD56, a marker for human NB. ${ }^{19,20}$ The results demonstrated that lungs and bone marrow of nude mice inoculated with nonmetastatic MHH or SY5Y NB cells harbored DisNB human cells.

It should be noted that the bone marrow of mice inoculated with metastatic cells that developed only lung macrometastases did harbor DisNB cells (Figure 2), although no overt metastasis was detected in this compartment. Similar results were obtained with the bone marrow and lung metastasizing SY5Y.Lu2 variant (data not shown).

RNA of cells cultured from lungs of mice inoculated with $\mathrm{MHH}$.Ad cells (the local NB tumor) and RNA of cells cultured from bone marrow of mice inoculated with $\mathrm{MHH}$.Ad or metastatic MHH.Lu3 cells was also analyzed by PCR using a human-specific segment of the plasminogen activator urokinase receptor (PLAUR) as a probe. The bone marrow from 6 of 10 mice inoculated with cells from the nonmetastatic variant produced a specific signal (Figure 2). Similar results were obtained with lungs of mice inoculated with cells from the nonmetastatic variant (Figure 2).

These results suggested that a very small number of NB cells, undetectable immunohistochemically, could find their way to the bone marrow and lungs of the inoculated mice. Seemingly, the lung microenvironment of NB inoculated nude mice may contain two types of NB cells. The one is capable of producing metastasis in this organ site, whereas the other does not form metastasis, but is capable of surviving in this site, possibly in a state of dormancy.

The working hypothesis that drove the present study is that these two types of NB cells express different molecular and functional signatures, and that defining these signatures will enable the identification of NB determinants that control, in a given microenvironment, dormancy on the one hand and propagation and progression toward metastasis on the other hand.

In subsequent experiments, we decided to focus on MetNB and DisNB cells that originated from the $\mathrm{MHH}$ tumor.

We have at our disposal two NB cell lines that outgrew from the lungs of two different nude mice inoculated with the nonmetastatic $\mathrm{MHH}$.Ad variant (designated hereafter as DisNB9 \& DisNB10), and two cell lines originating from lung metastasis of two different nude mice inoculated with the metastatic $\mathrm{MHH}$.Lu3 variant (designated hereafter as MetNB1 and MetNB2). 


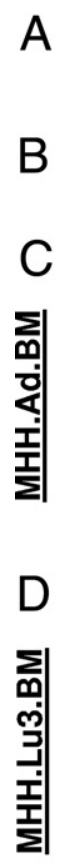
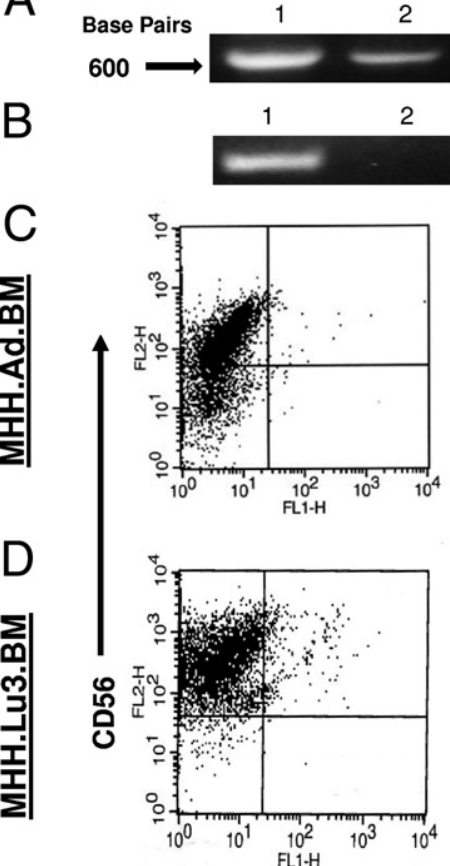

H-2 class I

$E$

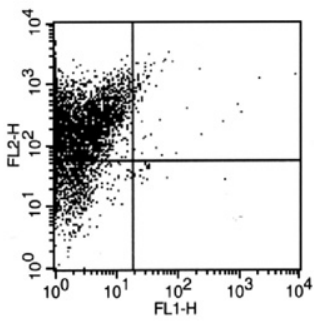

H-2 class I
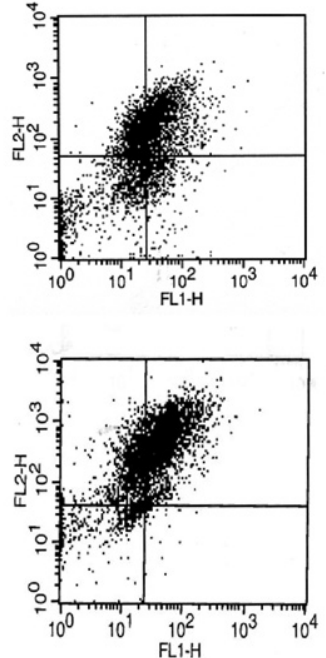

HLA class I

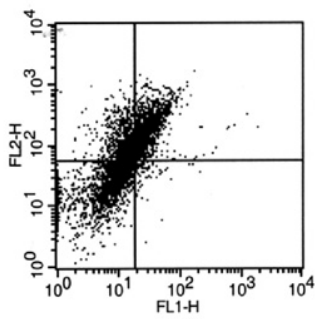

HLA class I

Figure 2. Lungs and bone marrow of nude mice inoculated with local and metastatic NB variants contain micro metastases (A, B) PCR analysis. Cells cultured from: bone marrow of mice inoculated with the metastatic (MHH.Lu3) and nonmetastatic (MHH.Ad) NB variants (A) or lungs of mice inoculated with MHH.Ad cells were cultured for approximately 40 days (B) and subjected to PCR analysis using specific primers against the human PLAUR gene. Cells cultured from bone marrow of mice inoculated with MHH.Ad cells (A, lane 1) bone marrow of mice inoculated with MHH.Lu3 cells (A, lane $\mathbf{2}$ ) or lungs of mice inoculated with MHH.Ad cells (B, lane $\mathbf{1}$ ). Lane $\mathbf{3}$ in panel $\mathbf{A}$ and lane $\mathbf{2}$ in panel $\mathbf{B}$ contain mouse mammary carcinoma DA3 cells (negative control) while lane $\mathbf{4}$ in panel $\mathbf{A}$ and lane $\mathbf{3}$ in panel $\mathbf{B}$ contain cultured human MHH-NB11 NB cells (positive control). C-E: Flow cytometry analysis of the NB cells that outgrew from 12- to 16-week-old cultures of bone marrow and lungs of mice inoculated orthotopically with MHH.Ad and MHH.Lu3 cells. Monoclonal antibodies against CD56 and against human and mouse major histocompatibility complex class 1 antigens were used. Cells were cultured from bone marrow of mice inoculated with MHH. Ad cells $(\mathbf{C})$ bone marrow of mice inoculated with MHH.Lu3 cells (D), and lungs of mice inoculated with MHH.Ad cells (E). The cells were positive for human leukocyte antigen (HLA) and human CD56 (right panel) but negative for mouse $\mathrm{H}-2$.

The phenotypic characterization of the DisNB and the MetNB cell subpopulations is described as follows.

\section{The Tumorigenic and Metastatic Capacity of Metastatic and DisNB Cells}

We determined the capacity of DisNB9, DisNB10, MetNB1, and MetNB2 cells to form local tumors in the

adrenal gland of nude mice, orthotopically inoculated with these cells and to generate distant metastases after such an inoculation.

The mice were sacrificed when moribund (70 to 134 days after inoculation). Mice that seemed healthy were sacrificed 150 days after the inoculation. There were no significant differences in the incidence of local adrenal tumors in mice inoculated, either with the metastatic NB variants Met1 and Met2 or with the disseminated (DisNB9 and DisNB10 variants, 55\% and 53\%, respectively). The survival time of both groups of inoculated mice was also similar (117 and 118 days, respectively).

A Real-time PCR assay developed for the quantification of minimal residual disease in the NB xenograft model was used to quantify the relative burden of NB cells in nude mice orthotopically inoculated either with DisNB cells or with MetNB cells. Figure 3 shows that MetNB variants produced a significantly higher NB cell burden (16-fold) in the lungs than that produced in this organ by the DisNB variants. A different situation existed with respect to the migration of the variants to bone marrow. Whereas small numbers of both MetNB and DisNB variants were detected in the bone marrow, there was only a nonsignificant (twofold) difference between them. This indicates that NB metastases produced in one organ are not necessarily equipped with the ability to survive or metastasize in another organ.

The in vivo results clearly indicate that both the metastatic and the DisNB cells are equally tumorigenic in the orthotopic site. However, a significantly higher number of cells were recovered in the lungs of mice inoculated with the MetNB variants than in the lungs of mice inoculated with the DisNB variants. It remains to be determined if the ability of the MetNB cells to survive and propagate in the lungs is the decisive property enabling these cells to form metastasis in this organ. It is also unknown at present if the lack of this property or its inhibition (possibly by microenvironmental factors) accounts for the dormancy of the DisNB cells in the lungs and for their inability to form metastasis in this organ.
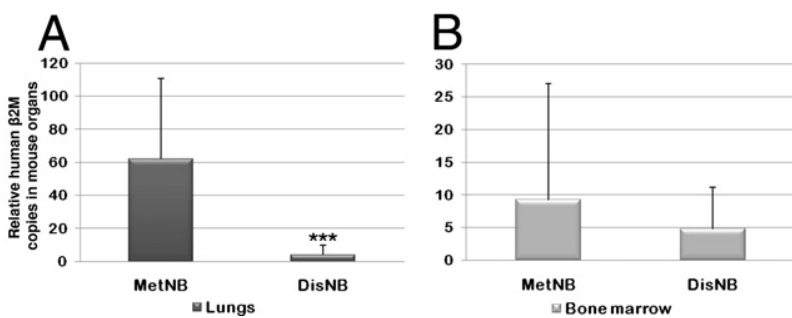

Figure 3. Relative mRNA levels of human cells in lungs and bone marrow of nude mice inoculated with metastasic neuroblastoma (MetNB) or disseminated neuroblastoma (DisNB) variants. Metastatic neuroblastoma (MetNB) and DisNB cells were inoculated orthotopically into the adrenal gland of nude mice. RT-PCR reaction shows high relative values of human $\beta 2 \mathrm{M}$ mRNA copies in the lungs (A) and bone marrows (B) of mice bearing the MetNB variants compared with the lungs of mice bearing tumors generated by the DisNB variants. The data are presented as mean $+\mathrm{SD}$. The higher relative values of human $\beta 2 \mathrm{M}$ mRNA copies in the lungs were statistically significant (****: $P<0.005)$ 


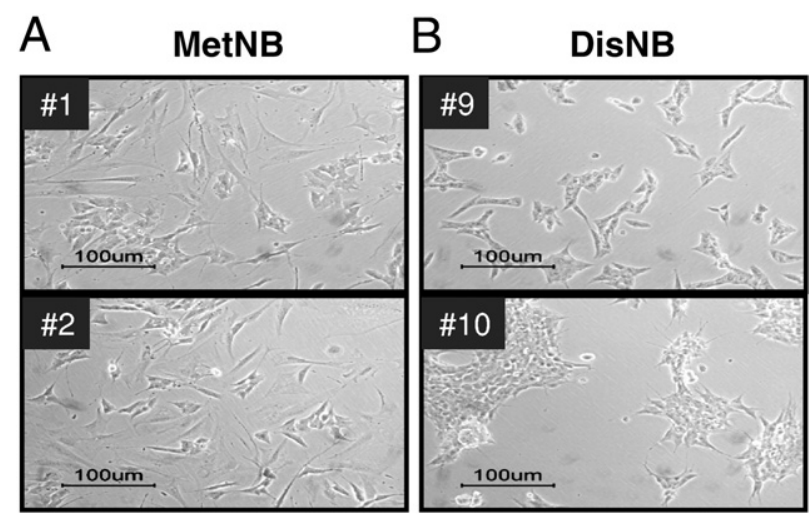

Figure 4. Distinct cell morphology of metastic neuroblastoma (MetNB) and disseminated neuroblastoma (DisNB) variants. Phase contrast photomicrographs of MetNB cells (A, variants \#1, \#2) and DisNB cells (B, variants \#9, \#10). Original magnification, $\times 10$.

\section{In Vitro Growth Characteristics of Metastatic and DisNB Cells}

Figure 4 demonstrates that DisNB and MetNB variants cells present distinct cell morphologies when grown in tissue culture. The growth pattern of DisNB cells resembles that of the cultured parental cell lines, namely these cells are small and grow as clumps. MetNB cells have a relatively flattened and elongated shape and form a monolayer.

XTT assays indicated that DisNB and MetNB variants do not differ in their proliferative capacity in vitro under normal culture conditions in serum-containing medium (data not shown).

\section{Surface Molecules Expressed by Metastatic and DisNB Cells}

\section{Minimal Residual Disease Markers}

RT-PCR is the most common method for the detection of minimal residual disease in NB using $\mathrm{TH}$ and $\mathrm{PHOX} 2 \mathrm{~B}$ as markers. ${ }^{21}$ We asked whether DisNB and MetNB cells differ in the expression level of these markers. As indicated in Figure 5, DisNB variants express significantly $\left({ }^{\star} P<0.05\right)$ higher levels of PHOX2B and TH mRNA as compared to MetNB variants. Results represent the mean $+S D$ of three independent experiments.

\section{Stem Cell Markers}

A relatively large proportion of disseminated tumor cells in certain types of cancer, mainly breast cancer, express phenotypic characteristics of cancer stem cells. ${ }^{22}$ Therefore, we compared the expression of some cancer stem cell markers by DisNB and MetNB cells.

CD133, c-kit (CD117), and CD34 are expressed by hematopoietic stem cells. ${ }^{23,24}$ CD133 is expressed on all fetal human neural stem cells ${ }^{25}$, whereas c-kit expression appears to be restricted to a subpopulation of neural crest stem cells. ${ }^{26}$

In pancreatic and colon cancer a high expression level of CD24 and CD44 characterizes cancer stem cells. ${ }^{27-29}$
Figure 6 shows that the expression of CD24 and CD133 was significantly higher $(P<0.05)$, in DisNB than in the MetNB variants, whereas the c-kit expression was significantly lower $(P<0.01)$ in DisNB than in the MetNB variants. Both DisNB and MetNB cells did not express CD34 or CD44.

\section{Chemokine Receptors}

As reported by us and by others, chemokine-chemokine receptor axes play important roles in the progression of NB. ${ }^{10-13,30,31}$ CXCR5 and CXCR6 were proposed as the main candidates to promote tumor invasion of the bone marrow through different mechanisms in NB. ${ }^{32}$ CX3CR1-CX3CL1 axis plays a functional role in transmigration of NB cells through bone marrow endothelium. ${ }^{12}$

Based on these reports we compared the expression of the CXCR3, CXCR4, CXCR5, CXCR6, and CX3CR1 chemokine receptors, as well as of the CX3CL1 chemokine, on DisNB and MetNB variants. Both types of variants expressed similar levels of CXCR3, CXCR4, and CX3CL1. Figure 7 shows that the expression of CXCR5, CXCR6, and CX3CR1 was lower on DisNB than on MetNB variants (CXCR5 $P<0.01$ and CX3CR1, $P<0.05$ ).

It is thus possible that the CXCR5-CXCL13, CXCR6CXCL16, and CX3CR1-CX3CL1 axes play a role in NB metastasis and that the low expression of the chemokine receptors on DisNB cells prevented their proliferation and transition to metastasis.

\section{CGNL1 Expression}

In a recent study we profiled the local and metastatic NB variants for gene expression patterns. ${ }^{14}$ The results of this study indicated that several genes were differentially expressed by these variants, as well as by stages 1 and 4 tumors from NB patients. We hypothesized that these genes may be involved in NB metastasis. One of the genes that were expressed at lower levels in the metastatic NB variants compared to the local ones and in stage 4 NB patients compared to stage 1 patients was Cingulin like one (CGNL1). CGNL1 is a tight junction component, the biological role of which in cancer is unknown.
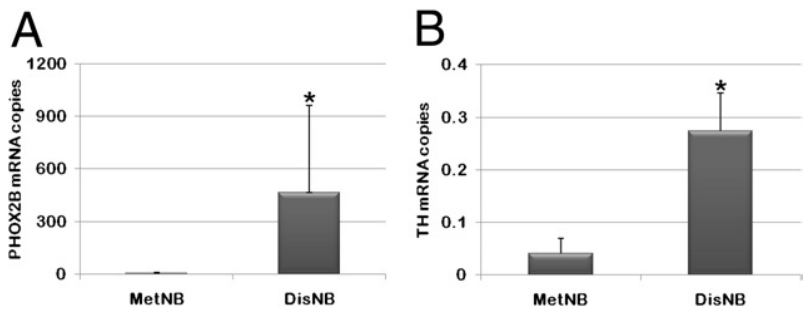

Figure 5. Higher expression level of minimal residual disease markers by variants of disseminated neuroblastoma (DisNB). Expression levels of minimal residual disease markers were tested by RT-PCR and were normalized to ribosomal RNA (rS9) as an internal control. Results indicate that the DisNB variants express significantly $\left({ }^{*} P<0.05\right)$ higher levels of PHOX2B $(\mathbf{A})$ and tyrosine hydroxylase (TH) mRNA (B) as compared to the metastic neuroblastoma (MetNB) variants. Results represent the mean $+\mathrm{SD}$ of three independent experiments. 

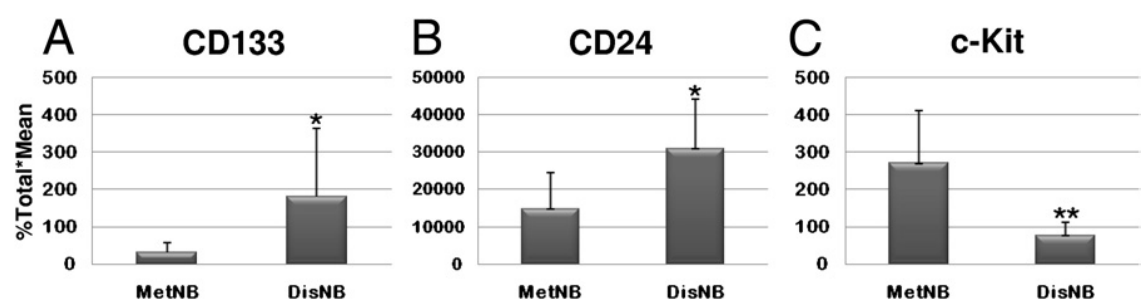

Figure 6. Expression level of stem cell markers by metastic neuroblastoma (MetNB) and disseminated neuroblastoma (DisNB) variants. Expression levels of stem cell markers on MetNB and DisNB variants were analyzed by flow cytometry. Cells were coated with antibodies against CD133 (A), CD24 (B), and c-Kit (C), followed by a secondary fluorescein isothiocyanate-conjugated anti-IgG antibody. Control samples were coated with secondary antibody only. Ordinate figures were derived by multiplying the percentage positive cells by the mean fluorescence per cell. Each graph represents the average $+\mathrm{SD}$ of the expression level obtained for each cell line in three or more independent experiments. The differences were statistically significant $\left({ }^{*} P<0.05\right.$, ** $P<0.01)$
CGNL1 expression level as shown in Figure 8 is 3.5fold lower in DisNB variants as compared to MetNB variants.

\section{Functional Characteristics of Metastatic and DisNB Cells}

\section{ERK and AKT Phosphorylation}

It is well-established that ERK and PI3 kinase pathways are deregulated in many types of cancer and are linked to increased proliferation, cell survival, angiogenesis, and motility, which are all key elements in tumor invasion and metastasis. ${ }^{33,34}$

We asked if DisNB and MetNB variants differ in the constitutive phosphorylation patterns of ERK and AKT. Figure 9 shows the results of a representative experiment in which MetNB variants had 3.3-fold higher ERK phosphorylation than DisNB variants. The results indicating that ERK signaling components are constitutively activated in MetNB variants, suggest that this activation may positively regulate various pro-malignancy functions of these cells. No differences in AKT activation between the MetNB and the DisNB variants were detected (data not shown).

\section{Migratory Capacity}

Enhanced migration of tumor cells is associated with and also leads to metastasis. ${ }^{35}$ Using the wound healing assay we compared the migratory ability of DisNB and MetNB variants. The results of this assay (Figure 10) showed that MetNB variants have a significantly higher rate of wound closure (100\% closure after 48 hours) than DisNB variants ( $47 \%$ and $51 \%$ closure after 48 hours).

\section{MMP Secretion}

A relatively high secretion of MMPs functioning as promalignancy factors, characterizes malignant cancer cells. These tumor-derived enzymes support the invasion of tumor cells through the basement membrane. ${ }^{36}$ Gelatin zymography was used to determine the activity of gelatinases (MMP-2 and MMP-9) secreted from DisNB and MetNB variants. The results in Figure 11 show that MetNB variants displayed a relatively higher activity level of the two gelatin-degrading enzymes $(70,78$, and 90 $\mathrm{kDa}$ ) than DisNB cells. Using Western blot analysis and antibodies directed against MMP-2 and MMP-9, we were able to identify the enzymes as the pro and the active form of MMP-2 and the active form of MMP-9 (data not shown).

\section{Sensitivity to Chemotherapy}

Doxorubicin (Dox) is a chemotherapeutic agent commonly used in the treatment of NB patients. ${ }^{37}$ Another agent used in in vitro studies, as well as in the clinical trials, is the iron ( $\mathrm{Fe}$ ) chelation therapy agent (DFX).

As previously indicated, DisNB and MetNB variants did not differ in their proliferative capacity in vitro under normal culture conditions. However, these two types of variants exhibited a different proliferative capacity under the influence of chemotherapy agents. Figure 12 shows
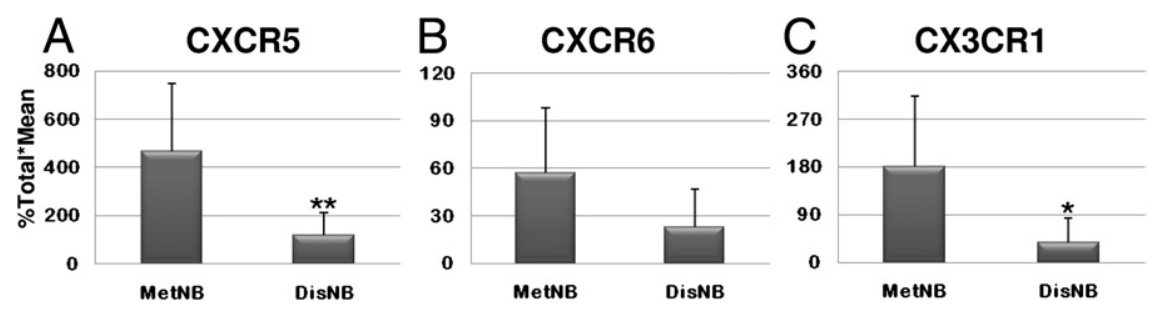

Figure 7. Expression level of chemokine receptors by metastic neuroblastoma (MetNB) and disseminated neuroblastoma (DisNB) variants. Expression levels of chemokine receptors on MetNB and DisNB variants were analyzed by flow cytometry. Cells were coated with antibodies against CXCR5 (A), CXCR6 (B), and CX3CR1 (C), followed by a secondary fluorescein isothiocyanate-conjugated anti-IgG antibody. Control samples were coated with secondary antibody only. Ordinate figures were derived by multiplying the percentage positive cells by the mean fluorescence per cell. Each graph represents the average + SD of the expression level obtained for each cell line in three or more independent experiments. The differences were statistically significant $\left({ }^{*} P<0.05,{ }^{* * *} P<0.01\right)$. 


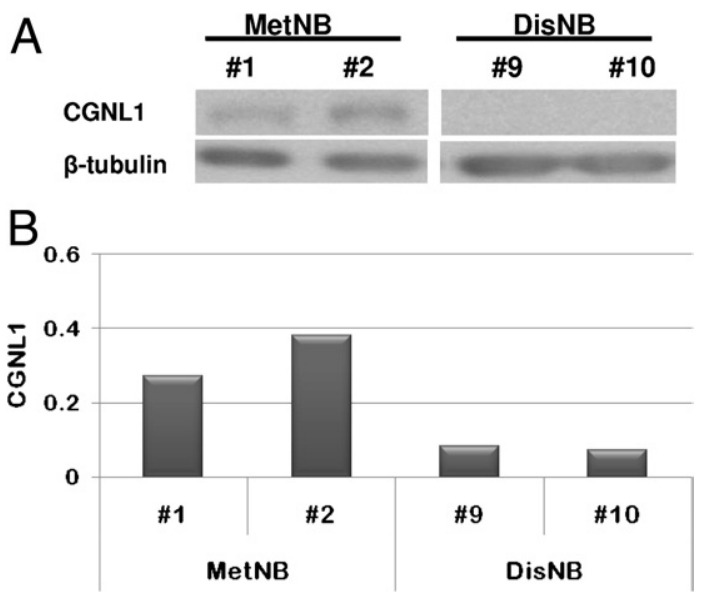

Figure 8. Higher expression levels of CGNL1 by metastic neuroblastoma (MetNB) as compared to the disseminated neuroblastoma (DisNB) variants CGNL1 and $\beta$-tubulin (loading control) expression by using Western blot analysis. A: Western blotting. B: Densitometry analysis. The results presented are a representative experiment of three independent ones.

that MetNB variants exhibited a significantly higher resistance to Dox and DFX $(P<0.05$ and $P<0.01$, respectively) than DisNB variants. Viability of the cells was determined by an XTT assay after 48 hours of exposure to $0.5 \mu \mathrm{mol} / \mathrm{L}$ Dox and $25 \mu \mathrm{mol} / \mathrm{L}$ DFX. Whereas the average viability of DisNB variants after the treatment with Dox and DFX (relative to the untreated controls) was $61 \%$ and $82 \%$, respectively, MetNB variants exhibited $91 \%$ and $100 \%$ viability. Phase contrast microscopy showed that DisNB variants are also more sensitive to low concentrations of Dox $(0.075 \mu \mathrm{mol} / \mathrm{L}$ and $0.125 \mu \mathrm{mol} / \mathrm{L})$ than MetNB cells (results not shown).
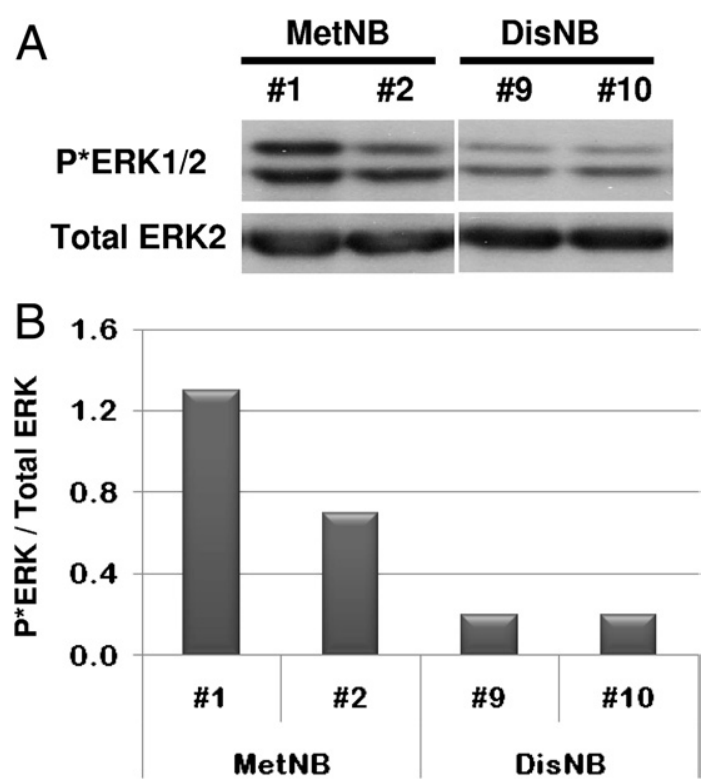

Figure 9. Higher mitogen-activated protein kinase signal activity in metastic neuroblastoma (MetNB) as compared to the disseminated neuroblastoma (DisNB) variants. MetNB and DisNB cells were cultured for 24 hours in serumfree medium. Whole cell lysates were subjected to the use of Western blot analysis. A: Phosphorylated extracellular regulated kinase (P*ERK)1/2 and total ERK2 were detected by specific antibodies. B: Phosphorylation was calculated in reference to the total ERK2, as measured by densitometry. The results presented are a representative experiment of three independent ones.

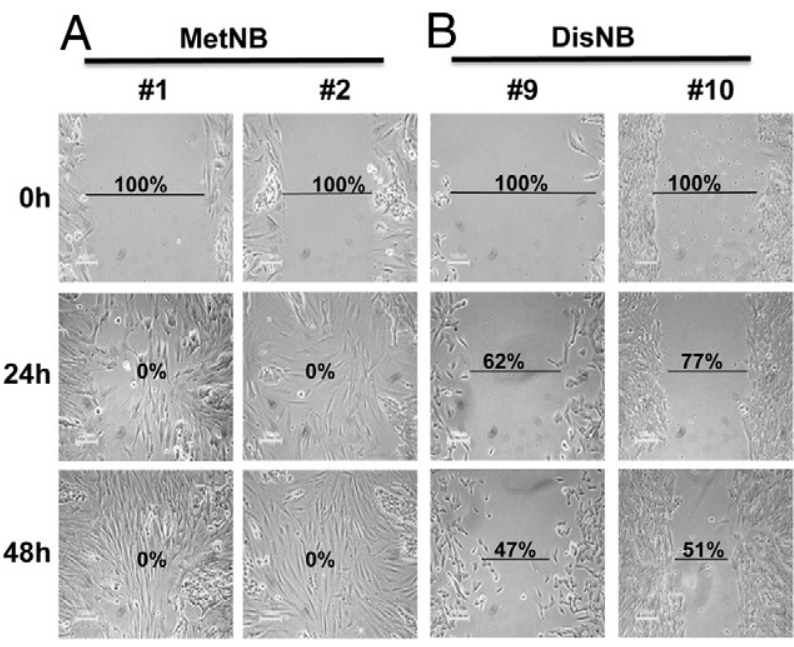

Figure 10. Higher migratory capacity of metastic neuroblastoma (MetNB) than of disseminated neuroblastoma (DisNB) variants. Phase contrast photomicrographs of scratched monolayers in a wound-healing assay of: MetNB (A) and DisNB (B) variant cells at 0,24, and 48 hours. The percentage of closure of the denuded area was calculated relatively to the space of each variant at the zero hour. Shown are representative photomicrographs (original magnification, $\times 10$ ) of three independent experiments.

\section{Discussion}

Tumor cells may circulate in the blood and disseminate into distant organs without forming overt metastasis.
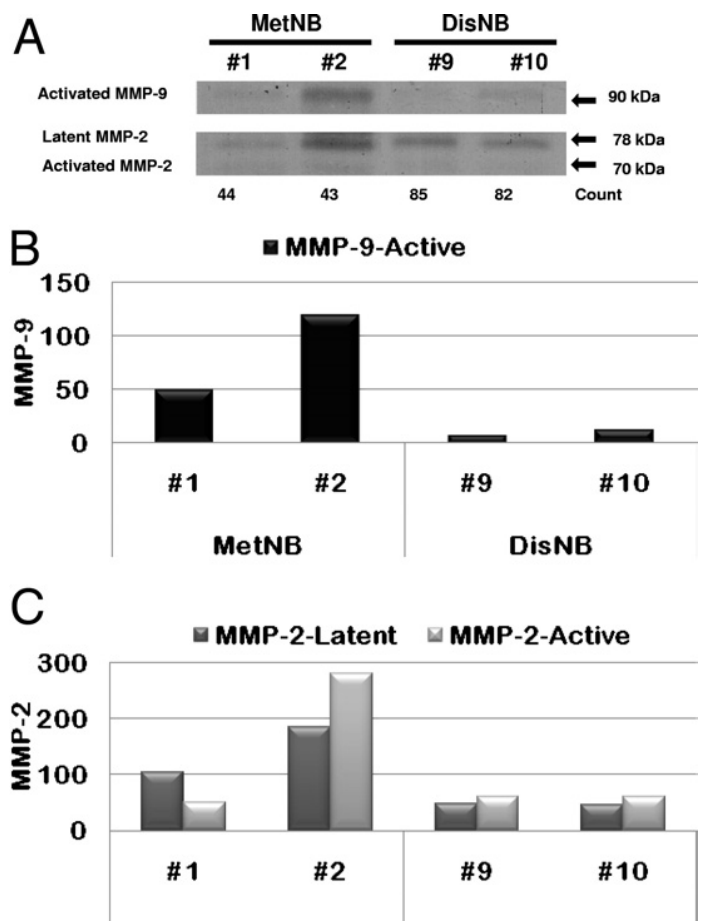

Figure 11. Higher matrix metalloproteinase (MMP)-2 and MMP-9 secretion by metastic neuroblastoma (MetNB) than by disseminated neuroblastoma (DisNB) variants. MetNB and DisNB variant cells were cultured without serum for 24 hours and subjected to gelatin zymography. A: The results of one representative experiment of four experiments are presented. The amounts of secreted MMP-2 (B) and MMP-9 (C) were determined by the arbitrary value of the gel densitometry relative to the number of cells that were left after the removal of the spent media. The MMP were identified by using Western blot analysis with antibodies against MMP2 and MMP9 (data not shown). 


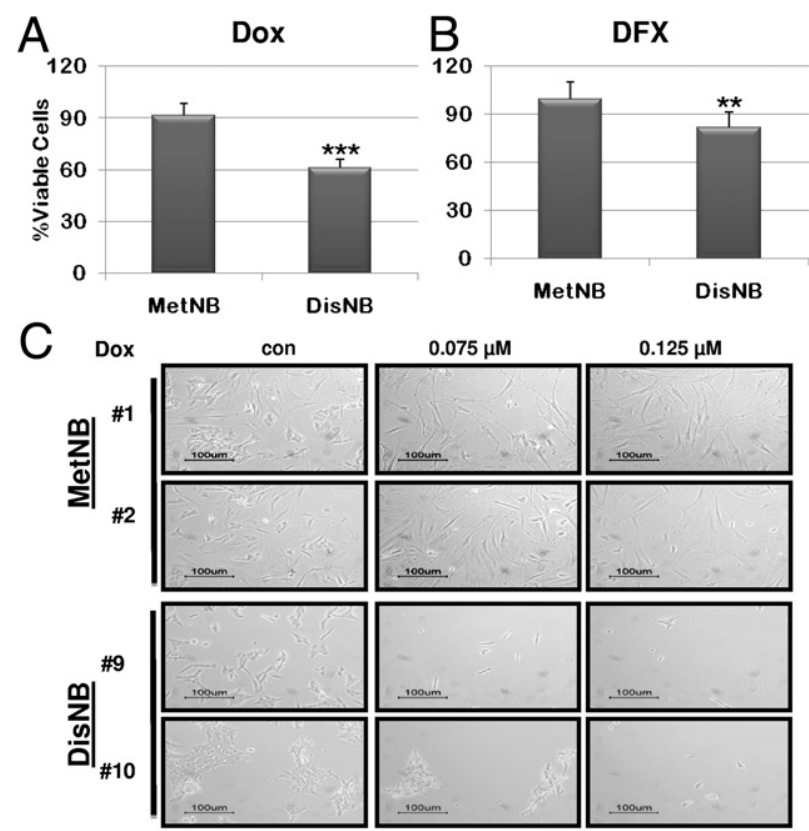

Figure 12. Sensitivity of metastic neuroblastoma (MetNB) and disseminated neuroblastoma (DisNB) variants to chemotherapy. Viability of the MetNB and DisNB variants was determined by the XTT assay following treatment with $0.5 \mu \mathrm{mol} / \mathrm{L}$ doxorubicin (Dox) (A) or $25 \mu \mathrm{mol} / \mathrm{L}$ desferrioxamine (DFX) (B) The graph represents the average ratio between the $\%$ viable chemotherapy treated cells divided by the $\%$ of viable untreated control cells. The presented results are the mean $+\mathrm{SD}$ of 3 independent experiments. The differences were statistically significant $\left({ }^{* *} P<0.005,{ }^{* * * * *} P<0.00005\right)$. C: The viability under the treatment with Dox $0.075 \mu \mathrm{mol} / \mathrm{L}$, and $0.125 \mu \mathrm{mol} / \mathrm{L}$ was also determined by phase contrast microscopy (original magnification, $\times 10$ ). The results presented are the representative pictures of three independent experiments.

Such cells are referred to as dormant tumor cells, micrometastases, or disseminated tumor cells. ${ }^{35,38,39}$ Minimal residual disease cells fall also into this category. The presence of disseminated tumor cells is linked to an increased risk of late metastatic relapse. ${ }^{40}$ Regional lymph node, bone marrow and lungs are known to harbor such cells. Of these sites, bone marrow and lungs have emerged as a common target organ for disseminated tumor cells, independent of the primary tumor site and the pattern of overt metastasis. ${ }^{41,42}$

In attempts to gain more insights into the metastatic process of NB, we developed an orthotopic xenograft model of human NB comprising local, nonmetastatic variants, as well as lung metastasizing variants. Both types of variants, originating from the same NB tumors, have an identical genetic background so that any genetic and proteomic or transcriptomic differences between them could be ascribed to the differential metastatic capacity of these variants. ${ }^{14}$

Although the metastatic variants orthotopically inoculated into the adrenal gland of nude mice form lung metastasis (50\%), we discovered in the present study that the nonmetastatic variants when inoculated into the same orthotopic site disseminate to lungs without producing overt metastasis in this organ $(0 \%)$. This provided a unique situation allowing a comparative analysis of two lung infiltrating NB cell subpopulations sharing the same genetic background that differ in their metastatic capacity in this same organ microenvironment.

Cellular NB variants were generated from both subpopulations. Variants generated from NB lung macrometastasis were designated as MetNB and NB variants isolated from lungs of mice inoculated with nonmetastatic NB cells were designated as DisNB, according to Aguirre-Ghiso. ${ }^{43}$

DisNB and local tumor cells differ in quite a few characteristics, and therefore constitute two different subpopulations. For example, DisNB cells showed a 33-fold higher expression level of the minimal residual disease marker $\mathrm{PHOX} 2 \mathrm{~B}$ than the $\mathrm{MHH}$ local variant $(P<0.05$, data not shown). This fact and the results of experiments (Materials and Methods) indicating that DisNB cells did not reach the lungs shortly after an intra-adrenal inoculation argue against the possibility that DisNB cells reached the mouse lungs via a systemic spread during the inoculation procedure.

Lung DisNB cells proliferated well in vitro. This demonstrates that the intrinsic capacity of these cells to proliferate was not impaired. We hypothesize that factors present in the lung microenvironment specifically inhibit the propagation of these disseminated tumor cells. Once removed from the restraining lung microenvironment, DisNB cells regained their ability to propagate. They are capable of forming adrenal tumors and proliferate well in vitro. Other studies have also shown that disseminated, dormant tumor cells are able to resume normal proliferation rates in vitro and form tumors in vivo after being released from specific in vivo microenvironments. ${ }^{44}$

Moreover, both MetNB, as well as DisNB variants recapitulate the in vivo malignancy behavior of their ancestor cells. Both were equally tumorigenic in the orthotopic inoculation site. Whereas MetNB variants formed spontaneous metastasis in the lungs (DisNB cells), although capable of migrating from the adrenal to the lungs, remain dormant in this secondary site. The different malignancy phenotype of MetNB and DisNB variants may be due to a differential response to signals delivered by the lung microenvironment.

The in vivo data clearly show that the DisNB cells express a lower malignancy phenotype than the MetNB cells. Some of the differential in vitro characteristics of these cells, such as a higher constitutive phosphorylation of MAPK, ${ }^{45}$ a higher MMP activity ${ }^{36}$ and a higher migratory capacity ${ }^{35}$ of the MetNB cells indeed support the in vivo data. However, the differential expression of other malignancy-associated characteristics in the two types of variants did not conform to expected differences between low and high malignancy tumor cells (Table 2). The following examples illustrate this point.

As dormant tumor cell populations may contain cancer stem cells, ${ }^{38}$ we profiled DisNB and MetNB cells for the expression of stem cell markers. Although the distinct cell morphology of DisNB variants (I-like-type phenotype) and the relatively high expression of CD133 and CD24 by these cells support the possibility that they are NB stem cells, ${ }^{46-48}$ the relatively low expression of $\mathrm{c}-\mathrm{Kit}^{46}$ and the absence of $\mathrm{CD} 34^{23}$ and CD44 ${ }^{49}$ expression by these cells cast a shadow of doubt on this possibility. 
Table 2. The Malignancy Phenotype of MetNB and DisNB Cell Variants

\begin{tabular}{|c|c|c|c|}
\hline \multicolumn{2}{|c|}{ Characteristics } & \multirow{2}{*}{$\begin{array}{l}\text { DisNB } \\
+\end{array}$} & \multirow{2}{*}{$\begin{array}{l}\text { MetNB } \\
+\end{array}$} \\
\hline Tumorigenicity and survival & & & \\
\hline Lung metastasis & & Very low & High \\
\hline Proliferation & & + & + \\
\hline Morphology* & & I-like & S-like \\
\hline \multirow[t]{2}{*}{ Minimal residual disease markers } & $\mathrm{PHOX} 2 \mathrm{~B}$ & Very high & Very low \\
\hline & & High & Low \\
\hline \multirow[t]{4}{*}{ Stem cell markers } & C-Kit & Low & High \\
\hline & CD24 & High & Low \\
\hline & CD133 & High & Low \\
\hline & CD44, CD34 & - & - \\
\hline \multirow[t]{2}{*}{ Chemokine receptors } & CXCR5, CXCR6, CX3CR1 & Low & High \\
\hline & CXCR3, CXCR4 & + & + \\
\hline \multicolumn{2}{|l|}{ Cingulin like 1} & Low & High \\
\hline \multicolumn{2}{|l|}{ Migration (wound healing) } & Low & High \\
\hline \multicolumn{2}{|l|}{ Secretion of MMP2 \& MMP9 } & Low & High \\
\hline \multirow[t]{2}{*}{ Constitutive phosphorylation } & $\mathrm{PI} 3 \mathrm{~K}\left(\mathrm{P}^{*} \mathrm{AKT}\right)$ & + & + \\
\hline & MAPK (P*ERK) & Low & High \\
\hline Sensitivity to chemotherapy & DFX and Dox & High & Low \\
\hline
\end{tabular}

The table summarizes similarities and differences between the metastasis neuroblastoma (MetNB) and the disseminated neuroblastoma (DisNB) variants.

*Human neuroblastoma (NB) cell lines present three cell phenotypic subtypes, the neuroblastic (N), the substrate adherent (S), and the intermediate (I) subtypes (have recently been proposed as NB stem cells) ${ }^{46}$.

DFX, desferrioxamine; Dox, doxorubicin; I-like, intermediate phenotype; MAPK, mitogen-activated protein kinase; $\mathrm{P}^{*} \mathrm{AKT}$, phosphorylated, v-akt murine thymoma viral oncogene homolog; $\mathrm{P}^{\star}$ ERK, phosphorylated extracellular regulated kinase; PHOX2B, paired-like Homeobox 2B; S-like, substrate-adherent phenotype; TH, tyrosine hydroxylase.

Previous studies from our laboratory and those of others have demonstrated that the chemokine receptors CXCR4, CXCR5, CXCR6, and CX3CR1 function as promalignancy factors in NB. ${ }^{10-12,30,31}$ CX3CR1, for example, is involved in transendothelial migration, a functional property of metastatic cells. ${ }^{12}$ CXCR3 was assigned an anti-malignancy. ${ }^{13}$ However, the results of this study indicated that the chemokine receptor expression pattern did not clearly segregate between DisNB and MetNB cells expressing a differential malignancy phenotype; both types of variants expressed similar levels of the anti-NB malignancy receptor CXCR3 and of the pro-malignancy CXCR4 receptor. On the other hand, the expression of CXCR5, CXCR6, and CX3CR1 was lower on DisNB cells than on MetNB cells, as expected.

In a recent report, we demonstrated that the tight junction protein Cingulin like 1 (CGNL1) whose biological function in cancer is currently unknown, is a component of a molecular signature of metastatic NB capable to segregate stage 1 from stage 4 NB patients. ${ }^{15}$ The expression of CGNL1 was lower in the high grade, stage 4 NB tumors than in stage 1 tumors. The expression of CGNL1 was also lower in the metastatic variants generated in our laboratory than in the local adrenal tumors. ${ }^{15}$ Surprisingly, the results of the present study indicated that DisNB variants, although exhibiting a lesser malignant phenotype in vivo than MetNB variants, expressed lower levels of CGNL1 than MetNB variants.

$\mathrm{PHOX} 2 \mathrm{~B}$ and $\mathrm{TH}$, minimal residual disease markers in $\mathrm{NB}^{50-52}$ are expressed by DisNB cells, but not by MetNB cells. These are essentially the only molecules detected in this study that characterize almost exclusively the former cells. The function of these molecules in the progression of NB cells, if any, is presently under investigation.

Nondividing dormant cells are resistant to chemotherapy. ${ }^{43,53}$ However, the DisNB cells seem to be dormant in vivo, in the xenografted mice, our data show that these cells were sensitive to Dox and DFX chemotherapy agents. A possible explanation for this result, as well as for the other examples previously detailed, is that some traits of the dormant DisNB cells may have been altered on the transfer of these cells from in vivo conditions enforcing dormancy to proliferation permissive culture conditions may have induced the expression of traits characterizing actively proliferating cells.

This explanation is supported by results demonstrating that cell cycle activated dormant cancer cells become exquisitely sensitive to killing by different chemotherapeutic agents. ${ }^{54}$ The resistance of MetNB cells to Dox and DFX chemotherapy agents might imply the existence of intrinsic death-resistance mechanisms that assist these cells to survive and propagate once they reach the lungs.

The properties that are shared by MetNB and DisNB cells may represent traits, although necessary, for pulmonary metastasis are by themselves insufficient to confer a fully-fledged malignancy phenotype. On the other hand, those traits expressed by MetNB variants, but not by DisNB variants (NB metastasis biomarkers), such as a high constitutive activation of MAPK, a high expression of CXCR5, CXCR6, and CX3CR1, a medium expression of CGNL1, and expression of the MMPs and of molecules that confer a high ability to migrate, might be required for the ability to form pulmonary metastasis.

We suggest that the characteristics that were expressed by DisNB, but not by MetNB, variants, such as a high expression level of minimal residual disease markers, may be required to keep the former cells in a dormant state.

What are DisNB cells? Based on the analysis of their phenotype and similarly to other investigators, ${ }^{43,55}$ we hypothesize that at some point (possibly shortly after the 
orthotopic inoculation into the adrenal) these NB cells emigrated from the adrenal into the lungs. During this migration, as well as at the secondary site, they may have undergone an independent molecular evolution, thereby acquiring the unique phenotype previously described. An identical scenario could be postulated for NB development and progression in human patients.

Are the DisNB cells pre-metastatic cells that eventually could progress to metastasis? It is not unlikely that such cells may progress to metastasis once the NB metastasis biomarkers have been acquired. In fact, it was reported that disseminated dormant tumor cells might acquire genomic alterations typical for fully metastatic cells. ${ }^{56}$ Another scenario by which pre-metastatic DisNB cells could progress to metastasis is when the microenvironment permits or supports tumor progression. Indeed indirect evidence previously reported suggests that lung microenvironmental factors keep the DisNB cells in check and inhibit their proliferation at this secondary site. A subpopulation of such cells might have the capacity to bypass such inhibitory blocks and progress to a higher level of malignancy.

It would be highly important to identify and characterize such microenvironment-derived blocking factors as they could have therapeutic potential for the treatment of NB residual disease.

Taken together the NB xenograft models previously described ${ }^{14}$ and in the present study may serve as important tools for the detection of metastatic and dormant NB cells and for their molecular characterization, and thus they may impact attempts to prevent NB metastasis.

\section{Acknowledgments}

The authors thank Dr. Leonor E. Leider-Trejo (Institute of Pathology, Tel-Aviv Sourasky Medical Center) for performing the immunohistochemical analyses and Drs. Naam Kariv and Mickey Harlev (Animal Care Facilities, Sackler Faculty of Medicine, Tel-Aviv University) for all the help with animal experiments. We also thank Mrs. Dafna Shryber for the ultrasound imaging.

\section{References}

1. Mullassery D, Dominici C, Jesudason EC, McDowell HP, Losty PD: Neuroblastoma: contemporary management. Arch Dis Childhood-E 2009, 94:177-185

2. Modak S, Cheung NKV: Neuroblastoma: therapeutic strategies for a clinical enigma. Cancer Treat Rev 2010, 36:307-317

3. Maris JM, Hogarty MD, Bagatell R, Cohn SL: Neuroblastoma. Lancet 2007, 369:2106-2120

4. Brodeur GM: Neuroblastoma. Amsterdam edition. New York: Elsevier, 2000, 1-583

5. Cowie F, Corbett R, Pinkerton CR: Lung involvement in neuroblastoma: incidence and characteristics. Med Pediatr Oncol 1997, 28:429-432

6. Kammen BF, Matthay KK, Pacharn P, Gerbing R, Brasch RC, Gooding CA: Pulmonary metastases at diagnosis of neuroblastoma in pediatric patients: CT findings and prognosis. AJR Am J Roentgenol 2001, 176:755-759

7. Reynolds CP: Detection and treatment of minimal residual disease in high-risk neuroblastoma. Pediatr Transplant 2004, 8:56-66
8. Brodeur GM: Neuroblastoma: biological insights into a clinical enigma. Nat Rev Cancer 2003, 3:203-216

9. Kuroda T, Morikawa N, Matsuoka K, Fujino A, Honna T, Nakagawa A, Kumagai M, Masaki H, Saeki M: Prognostic significance of circulating tumor cells and bone marrow micrometastasis in advanced neuroblastoma. J Pediatr Surg 2008, 43:2182-2185

10. Geminder H, Sagi-Assif O, Goldberg L, Meshel T, Rechavi G, Witz IP, Ben-Baruch A: A possible role for CXCR4 and its ligand, the CXC chemokine stromal cell-derived factor-1, in the development of bone marrow metastases in neuroblastoma. J Immunol 2001, 167:47474757

11. Nevo I, Sagi-Assif O, Meshel T, Geminder H, Goldberg-Bittman L, Ben-Menachem S, Shalmon B, Goldberg I, Ben-Baruch A, Witz IP: The tumor microenvironment: cXCR4 is associated with distinct protein expression patterns in neuroblastoma cells. Immunol Lett 2004 , 92:163-169

12. Nevo I, Sagi-Assif O, Meshel T, Ben-Baruch A, Johrer K, Greil R, Trejo LE, Kharenko O, Feinmesser M, Yron I, Witz IP: The involvement of the fractalkine receptor in the transmigration of neuroblastoma cells through bone-marrow endothelial cells. Cancer Lett 2009, 273:127-139

13. Goldberg-Bittman L, Sagi-Assif O, Meshel T, Nevo I, Levy-Nissenbaum O, Yron I, Witz IP, Ben-Baruch A: Cellular characteristics of neuroblastoma cells: regulation by the ELR-CXC chemokine CXCL10 and expression of a CXCR3-like receptor. Cytokine 2005, 29:105-117

14. Nevo I, Sagi-Assif O, Edry Botzer L, Amar D, Maman S, Kariv N, Leider-Trejo LE, Savelyeva L, Schwab M, Yron I, Witz IP: Generation and characterization of novel local and metastatic human neuroblastoma variants. Neoplasia 2008, 10:816-827

15. Nevo I, Oberthuer A, Botzer E, Sagi-Assif O, Maman S, PasmanikChor M, Kariv N, Fischer M, Yron I, Witz IP: Gene-expression-based analysis of local and metastatic neuroblastoma variants reveals a set of genes associated with tumor progression in neuroblastoma patients. Int J Cancer 2010, 126:1570-1581

16. Pietsch T, Gottert E, Meese E, Blin N, Feickert HJ, Riehm H, Kovacs G: Characterization of a continuous cell line (MHH-NB-11) derived from advanced neuroblastoma. Anticancer Res 1988, 8:1329-1333

17. Parham P, Barnstable CJ, Bodmer WF: Use of a monoclonal antibody (W6/32) in structural studies of HLA-A,B,C, antigens. J Immunol 1979 123:342-349

18. Ozato K, Sachs DH: Monoclonal antibodies to mouse MHC antigens. III Hybridoma antibodies reacting to antigens of the $\mathrm{H}-2 \mathrm{~b}$ haplotype reveal genetic control of isotype expression. J Immunol 1981, 126: 317-321

19. Warzynski MJ, Graham DM, Axtell RA, Higgins JV, Hanmers YA: Flow cytometric immunophenotyping test for staging/monitoring neuroblastoma patients. Cytometry 2002, 50:298-304

20. Warzynski MJ, Graham DM, Axtell RA, Higgins JV, Hammers YA: Flow cytometric immunophenotyping test for staging/monitoring neuroblastoma patients. Cytometry 2000, 42:324-325

21. Kagedal B: Detecting minimal residual disease in neuroblastoma: still a ways to go. Clin Chem 2009, 55:1268-1270

22. Fehm T, Muller V, Alix-Panabieres C, Pantel K: Micrometastatic spread in breast cancer: detection, molecular characterization and clinical relevance, Breast Cancer Res 2008, 10(Suppl 1):S1

23. Donovan J, Temel J, Zuckerman A, Gribben J, Fang JJ, Pierson G, Ross A, Diller L, Grupp SA: CD34 selection as a stem cell purging strategy for neuroblastoma: preclinical and clinical studies. Medical and Pediatric Oncology 2000, 35:677-682

24. Wognum AW, Eaves AC, Thomas TE: Identification and isolation of hematopoietic stem cells. Arch Med Res 2003, 34:461-475

25. Luo R, Gao J, Wehrle-Haller B, Henion PD: Molecular identification of distinct neurogenic and melanogenic neural crest sublineages. Development 2003, 130:321-330

26. Hemmati HD, Nakano I, Lazareff JA, Masterman-Smith M, Geschwind $\mathrm{DH}$, Bronner-Fraser M, Kornblum HI: Cancerous stem cells can arise from pediatric brain tumors, P Natl Acad Sci USA 2003, 100:1517815183

27. Gaviraghi M, Tunici P, Valensin S, Rossi M, Giordano C, Magnoni L, Dandrea M, Montagna L, Ritelli R, Scarpa A, Bakker A: Pancreatic cancer spheres are more than just aggregates of stem marker positive cells. Biosci Rep 2010, 31:45-55 
28. Riethdorf S, Wikman H, Pantel K: Review: biological relevance of disseminated tumor cells in cancer patients. Int J Cancer 2008, 123:1991-2006

29. Orian-Rousseau V: CD44, a therapeutic target for metastasising tumours. Eur J Cancer 2010, 46:1271-1277

30. Airoldi I, Cocco C, Morandi F, Prigione I, Pistoia V: CXCR5 may be involved in the attraction of human metastatic neuroblastoma cells to the bone marrow. Cancer Immunol Immun 2008, 57:541-548

31. Gross N, Meier R: Chemokines in neuroectodermal cancers: the crucial growth signal from the soil. Semin Cancer Biol 2009, 19: 103-110

32. Raffaghello L, Cocco C, Corrias MV, Airoldi I, Pistoia V: Chemokines in neuroectodermal tumour progression and metastasis. Semin Cancer Biol 2009, 19:97-102

33. Vivanco I, Sawyers CL: The phosphatidylinositol 3-Kinase AKT pathway in human cancer. Nat Rev Cancer 2002, 2:489-501

34. Brader S, Eccles SA: Phosphoinositide 3-kinase signalling pathways in tumor progression, invasion and angiogenesis. Tumori 2004, 90:2-8

35. Nguyen DX, Bos PD, Massague J: Metastasis: from dissemination to organ-specific colonization. Nat Rev Cancer 2009, 9:274-284

36. Roy R, Yang J, Moses MA: Matrix Metalloproteinases As Novel Biomarkers and Potential Therapeutic Targets in Human Cancer. J Clin Oncol 2009, 27:5287-5297

37. Fulda S, Honer M, Menke-Moellers I, Berthold F: Antiproliferative potential of cytostatic drugs on neuroblastoma cells in vitro. Eur $\mathrm{J}$ Cancer 1995, 31A:616-621

38. Coghlin C, Murray Gl: Current and emerging concepts in tumour metastasis. J Pathol 2010, 222:1-15

39. Pantel K, Alix-Panabieres C: Circulating tumour cells in cancer patients: challenges and perspectives. Trends Mol Med 2010, 16: 398-406

40. Pantel K, Alix-Panabieres C: The clinical significance of circulating tumor cells. Nat Clin Pract Oncol 2007, 4:62-63

41. Husemann Y, Geigl JB, Schubert F, Musiani P, Meyer M, Burghart E, Forni G, Eils R, Fehm T, RiethmUller G, Klein CA: Systemic spread is an early step in breast cancer. Cancer Cell 2008, 13:58-68

42. Alix-Panabieres $\mathrm{C}$, Riethdorf S, Pantel K: Circulating tumor cells and bone marrow micrometastasis. Clin Cancer Res 2008, 14:5013-5021

43. Aguirre-Ghiso JA: Models, mechanisms and clinical evidence for cancer dormancy. Nat Rev Cancer 2007, 7:834-846

44. Naumov GN, MacDonald IC, Weinmeister PM, Kerkvliet N, Nadkarn KV, Wilson SM, Morris VL, Groom AC, Chambers AF: Persistence of solitary mammary carcinoma cells in a secondary site: a possible contributor to dormancy. Cancer Res 2002, 62:2162-2168
45. Viala E, Pouyssegur J: Regulation of tumor cell motility by ERK mitogen-activated protein kinases. Ann NY Acad Sci 2004, 1030:208-218

46. Ross RA, Spengler BA: Human neuroblastoma stem cells. Semin Cancer Biol 2007, 17:241-247

47. Tong QS, Zheng LD, Tang ST, Ruan QL, Liu Y, Li SW, Jiang GS, Cai JB: Expression and clinical significance of stem cell marker CD133 in human neuroblastoma. World J Pediatr 2008, 4:58-62

48. Hansford LM, McKee AE, Zhang L, George RE, Gerstle JT, Thorner PS, Smith KM, Look AT, Yeger H, Miller FD, Irwin MS, Thiele CJ, Kaplan DR: Neuroblastoma cells isolated from bone marrow metastases contain a naturally enriched tumor-initiating cell. Cancer Res 2007, 67:11234-11243

49. Woodward WA, Sulman EP: Cancer stem cells: markers or biomarkers? Cancer Metastasis Rev 2008, 27:459-470

50. Kuci Z, Seitz G, Kuci S, Kreyenberg H, Schumm M, Lang P, Niethammer D, Handgretinger R, Bruchelt G: Pitfalls in detection of contaminating neuroblastoma cells by tyrosine hydroxylase RT-PCR due to catecholamine-producing hematopoietic cells. Anticancer Res 2006, 26:2075-2080

51. Viprey VF, Corrias MV, Kagedal B, Oltra S, Swerts K, Vicha A, Ladenstein R, Burchill SA: Standardisation of operating procedures for the detection of minimal disease by QRT-PCR in children with neuroblastoma: quality assurance on behalf of SIOPEN-R-NET. Eur J Cancer 2007, 43:341-350

52. Stutterheim J, Gerritsen A, Zappeij-Kannegieter L, Kleijn I, Dee R, Hooft L, van Noesel MM, Bierings M, Berthold F, Versteeg R, Caron $\mathrm{HN}$, van der Schoot CE, Tytgat GA: PHOX2B is a novel and specific marker for minimal residual disease testing in neuroblastoma. J Clin Oncol 2008, 26:5443-5449

53. Naumov GN, Townson JL, MacDonald IC, Wilson SM, Bramwell VH Groom AC, Chambers AF: Ineffectiveness of doxorubicin treatment on solitary dormant mammary carcinoma cells or late-developing metastases. Breast Cancer Res Treat 2003, 82:199-206

54. Essers MA, Trumpp A: Targeting leukemic stem cells by breaking their dormancy. Mol Oncol 2010, 4:443-450

55. Enderling $H$, Hlatky L, Hahnfeldt P: Migration rules: tumours are conglomerates of self-metastases. Br J Cancer 2009, 100:1917-1925

56. Schmidt-Kittler O, Ragg T, Daskalakis A, Granzow M, Ahr A, Blankenstein TJ, Kaufmann M, Diebold J, Arnholdt H, Muller P, Bischoff J, Harich D, Schlimok G, Riethmuller G, Eils R, Klein CA: From latent disseminated cells to overt metastasis: genetic analysis of systemic breast cancer progression, Proc Natl Acad Sci USA 2003, 100:77377742 